$R M x A C, \mathbf{5 2}, 29-29(2020)$

(C) 2020: Instituto de Astronomía, Universidad Nacional Autónoma de México

https://doi.org/10.22201/ia.14052059p.2020.52.13

\title{
OAFA: THE PLACE UNDER THE SKY OF THE ANDES THAT HOUSES THE MASTER
}

R. C. Podestá ${ }^{1}$, V. M. Lipunov ${ }^{2}$, F. M. Podestá ${ }^{1}$, J. Quinteros ${ }^{1}$, A. M. Pacheco ${ }^{1}$, E. P. A. González ${ }^{1}$,

C. N. Francile ${ }^{1}$, J. Pérez ${ }^{1}$, L. Marmolejo ${ }^{1}$, J. Sedeño ${ }^{1}$, J. Navarro ${ }^{1}$, F. De La Jara ${ }^{1}$, and V. Rivero ${ }^{1}$

This paper shows the infrastructure and discoveries made by Russian instruments installed in the Carlos U. Cesco high altitude station.

The OAFA high altitude station (Cesco Station) is located in the Andes Mountains at 2,500 meters above sea level. It has a dry and arid climate, with excellent sky conditions. Inaugurated in 1965 by Yale University, it now belongs to National University of San Juan. It was originally dedicated to astrometry, although also devoted to astrophysical and solar investigations. The Felix Aguilar Astronomical Observatory (OAFA) in Argentina and the Moscow State University in Russia, celebrated in 2016 the renewal of an agreement of international cooperation and signed for the installation of a system of electronic cameras called MASTER I and MASTER II, located in OAFA's Cesco Station. According to the agreement, a dome was built to house the cameras Master I and Master II, together named as MASTER-OAFA (Lat $\left.=31.48^{\circ} \mathrm{S}, \mathrm{Lon}=69.20^{\circ} \mathrm{W}\right)$. These telescopes began operating within the MASTER global network from June 2016, working regularly under the excellent sky of the Argentinian Andes. From this site GRB and novas have been detected (Buckley et al. 2018) also contributing to the MPC with asteroids positions (Figure 1). The biggest discovery made to the present date was the kilonova (Figure 2), that resulted from the merger of two neutron stars in NGC 4993 galaxy (Abbott et al. 2017; Lipunov et al. 2017). The MASTER Global Robotic Network is a fast pointing alert and followup system, located in both Northern and Southern hemispheres, very suitable to investigate large fields of view in short time, with its own real-time optical transients auto-detection software.

\section{REFERENCES}

Abbott, B. P., Abbott, R., Abbott, T. D., et al. 2017, Natur, 551, 85

\footnotetext{
${ }^{1}$ Observatorio Astronómico Félix Aguilar, Universidad Nacional de San Juan, Benavidez 8175 Oeste, Chimbas 5413, San Juan, Argentina (ricpod@hotmail.com).

${ }^{2}$ Lomonosov Moscow State University Physics Department.
}

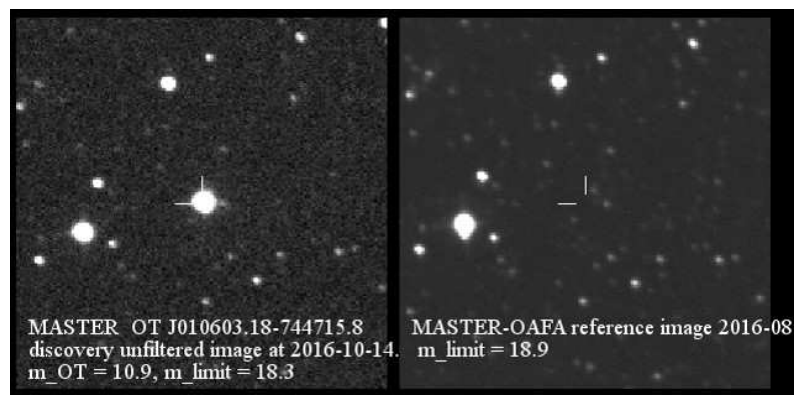

Fig. 1. Nova discovered with Master in Argentina.
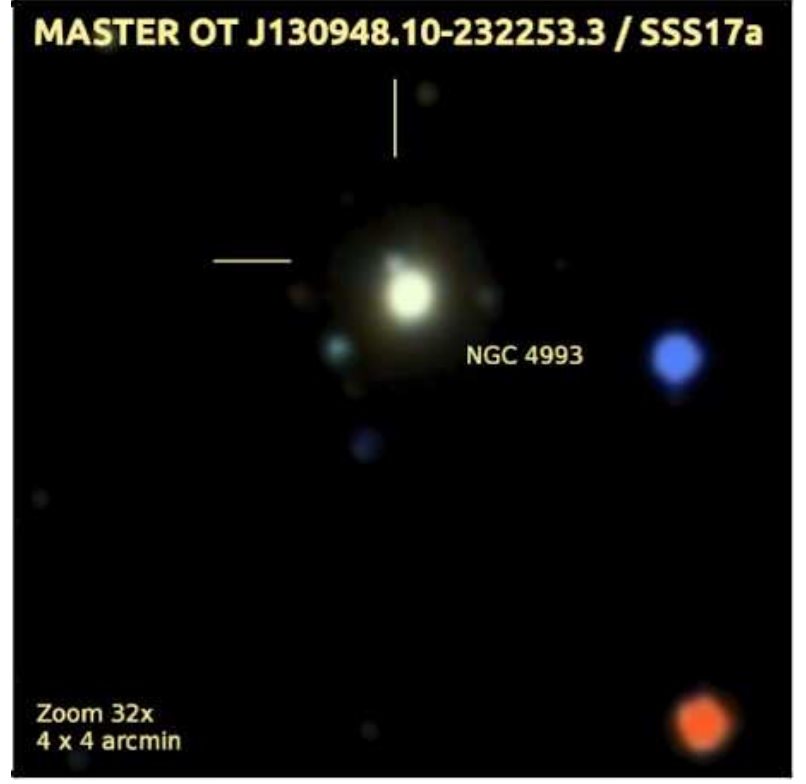

Fig. 2. Merger of two neutron stars in NGC 4993.

Buckley, D. A. H., Andreoni, I., Barway, S., et al. 2018, MNRAS, 474, L71

Lipunov, V. M., Gorbovskoy, E., Kornilov, V. G., et al. 2017, ApJ, 850, L1 